\title{
New technique for treating occlusive and stenosing tumours of the trachea and main bronchi: endobronchial irradiation by high dose iridium-192 combined with laser canalisation
}

\author{
H N MACHA, K KOCH, M STADLER, W SCHUMACHER, D KRUMHAAR \\ From the Department of Chest Diseases, Lungenklinik Hemer, Hemer; the Department of Chest Diseases, \\ Municipal Hospital, Havelhohe; and the Department of Radiology, Rudolf-Virchow-Krankenhaus, Berlin, \\ West Germany
}

\begin{abstract}
A new technique is described for treating patients with inoperable malignant tumours causing occlusion or stenosis of the trachea or main bronchi. High dose iridium-192 $(20 \mathrm{Ci})$ was introduced by an afterloading device under computer control via a $4 \mathrm{~mm}$ delivery tube into the tumour mass. In 29 of the 56 patients the tumour mass was canalised by a neodymium-YAG laser immediately before the afterloading delivery tube was introduced. In $44(79 \%)$ of the patients, there was impressive relief of dyspnoea, accompanied by tumour regression observed at endoscopy and also by highly significant improvement in ventilatory function values, lung perfusion scans, and levels of arterial oxygen tension. In the other 12 patients $(21 \%)$ there was no detectable improvement. The findings suggest that this recently developed combination treatment is of value in patients with advanced tumours of the trachea and main bronchi in whom there is no possibility of further treatment by external irradiation or repeated laser coagulation.
\end{abstract}

\section{Introduction}

The most important consideration in the palliative treatment of inoperable malignant tumours causing stenosis or occlusion of the trachea or main bronchi is the restoration of patency of the airway to relieve distress from dyspnoea.

Removal at endoscopy of as much of the tumour mass as possible by biopsy forceps, usually combined with cryosurgery, ${ }^{1}$ electrocautery, ${ }^{2}$ or laser coagulation, ${ }^{3-6}$ can achieve only limited clearance since this is restricted by the bronchial wall, and therefore relief is usually short lived.

Irradiation offers the possibility of obtaining longer periods of remission. External palliative radiation is effective in the treatment of superior vena cava obstruction or haemoptysis, but is much less effective for treating occluded bronchi with associated atelectasis. ${ }^{7}$ Implantation of radioactive agents close

Address for reprint requests: Dr $\mathbf{H}$ N Macha, Pneumologische Abteilung, Lungenklinik Hemer, 5870 Hemer, West Germany.

Accepted 9 December 1986 to the tumour has been used in three techniques. The first to be used was temporary endobronchial brachytherapy, in which cobalt-60 or radon-222 was placed as close as possible to the tumour. The limitations of that technique were the necessity for general anaesthesia and the long exposure times required for cobalt-60 (four hours) and radon-222 (18 hours), with consequent hazards from radiation to operators and assistants. ${ }^{8}$ The second technique, implantation of, for example, gold radioactive grains in the tumour mass at endoscopy, ${ }^{9}$ also usually requires general anaesthesia; but its major disadvantage is the necessity for strict precautions to be maintained for a prolonged period to avoid the dangers of radiation from the patients themselves and from their sputum. Similar considerations apply to the third technique, operative interstitial brachytherapy, in which radioactive grains are implanted within the tumour mass at thoracotomy. ${ }^{1011}$

In 1979 the Sauerwein afterloading device became available for endobronchial treatment. The problem of the radiation exposure to operators and assistants could thus be eliminated. By combining this technique with the introduction of iridium-192 Hilaris ${ }^{12}$ 
reduced the exposure time for endobronchial irradiation to a few 20 minute periods. The treatment could be performed under local anaesthesia. Since, however, the afterloading catheter had to be introduced through a tube of $9 \mathrm{~mm}$ internal diameter, it was impossible to place it in an optimal position of proximity to tumour that had nearly or completely occluded a bronchus. ${ }^{13}$

The technique described here overcomes this problem by using a delivery tube of only $4 \mathrm{~mm}$ external diameter and $60 \mathrm{~cm}$ length directly under view by the flexible fibrescope. The procedure can be carried out under local anaesthesia. For tumours causing complete occlusion, laser coagulation by neodymiumYAG laser (MBB, Munich) was first performed to canalise the tumour mass so that the afterloading tube could be placed in an optimal position for irradiation of the whole tumour.

Our observations in 56 patients with central obstructing tumours who were treated by this new combination treatment form the basis of this report.

\section{Patients and methods}

Since June 1983 we have used this technique to treat 56 patients with inoperable tumours of the trachea and main bronchi. Dyspnoea was the predominant symptom in all the 56 patients ( 44 men, mean age 62.8 years; 12 women, mean age $71 \cdot 1$ years). Nineteen patients had previously been treated with external irradiation (mean dose 62.5 Gy (6250 rad)), of whom two had not tolerated the side effects of previous cytotoxic treatment and three others had had laser coagulation at rapidly decreasing intervals. The tumour was in the right main bronchus in 33 patients, in the left main bronchus in 20 patients, and in the trachea in three patients. In 25 patients there was atelectasis distal to the tumour. The most common tumour was squamous cell carcinoma, which occurred in $71 \%$ of the men and $50 \%$ of the women. Five patients had adenoid-cystic carcinoma. Most of the tumours

Table 1 Tumour stage of 56 patients treated by the endobronchial afterloading technique using high dose iridium-192 in combination with the neodymium-YAG laser

$\left.\begin{array}{lrc}\hline \text { TNM staging } & \text { No } & \% \\
\hline \text { T2N1M0 } & 2 \\
\text { T2N2M0 } & 4 \\
\text { T3N0M0 } & 2 \\
\text { T3N1M0 } & 18 \\
\text { T3N2M0 } & 12\end{array}\right\}$\begin{tabular}{c}
$10 \cdot 7$ \\
T2N1M1 \\
T2N2M1 \\
T3N1M1 \\
T3N2M1 \\
Total \\
\hline
\end{tabular}

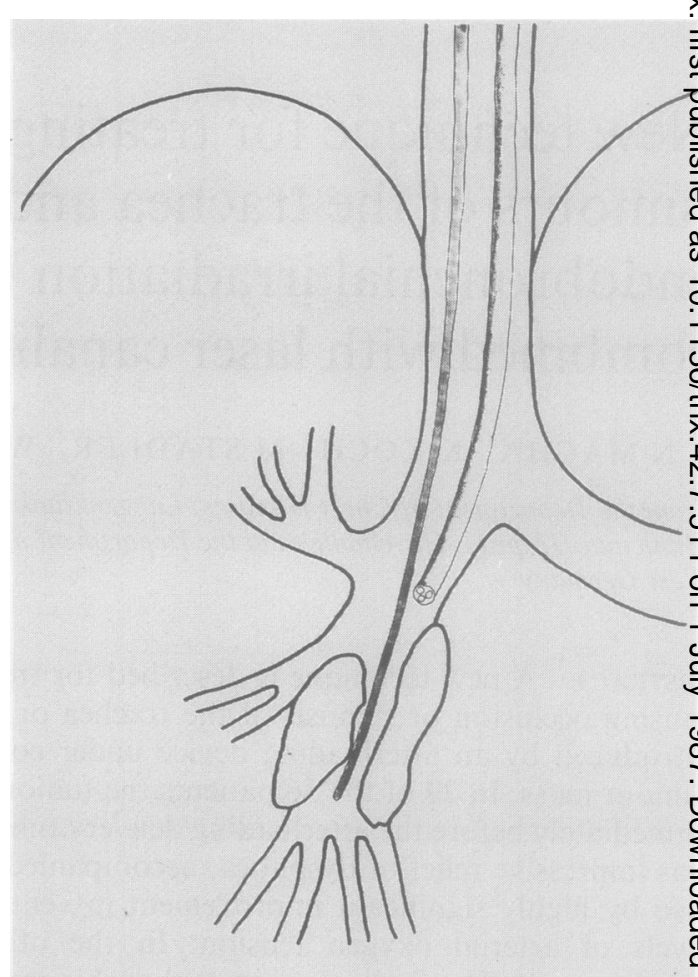

Fig 1 Introduction of the afterloading applicator under control by a fibreoptic bronchoscope.

$(57 \%)$ were in stage $\mathrm{T} 3 \mathrm{~N} 1$ and $\mathrm{N} 2 ; 32 \%$ of the patients had distant metastases (table 1). In four patients stenosis was caused by the recurrence of $\overrightarrow{\mathrm{Q}}$ resected carcinoma in a bronchial stump.

After local anaesthesia bronchoscopy was peio formed with a fibreoptic bronchoscope. After deter mination of the length of the area to be irradiated, the afterloading catheter was introduced via the mout and positioned at the site of stenosis under dires vision through the fibreoptic bronchoscope (fig 1).

After additional control of its position by fluoro? scopy the catheter was connected to the afterloadin device. Operator and assistants then left the radiation protected operating theatre and the irradiation pros cedure was started. There was visual and acoust $\mathbb{E}_{5}$ contact with the patient. The apparatus we used fow this investigation was the Gamma-Med II of the Isotopen-Technik GmbH Sauerwein, Haan, Wesf Germany. This is a single channel remote controlled afterloading device for a high activity source of very small dimensions. The apparatus is battery powered to ensure uninterrupted operation; the $220 \mathrm{~V}$ or 110 supply is required for the batteries only.

The iridium-192 source capsule (stainless steef with a specific activity of $20 \mathrm{Ci}$ (Mallinckrodt Diag nostica, Petten, The Netherlands) is only $8.5 \mathrm{~mm}$ lom 
and $1.1 \mathrm{~mm}$ in diameter. Its active dimensions are $5.0 \mathrm{~mm}$ in length and $0.5 \mathrm{~mm}$ in diameter. The source capsule is welded to a stainless steel source cable that is moved by a high reliability friction drive. This mechanism in conjunction with a stepper motor moves the source precisely out of its shielding into the desired treatment position inside the applicator. The accuracy of the source is independently monitored. The maximum treatment distance is $20 \mathrm{~cm}$. To achieve the appropriate isodose distribution the source can be moved in increments from 1 to $10 \mathrm{~mm}$ and the dwell time (from 0 to 1000 seconds) can be selected at each position.

In our investigation we used $5 \mathrm{~mm}$ steps and dwell times from 5 to 9 seconds, depending on the age of the iridium source. Figure 2 shows as an example the distribution of the isodose curves for an irradiation of a $6 \mathrm{~cm}$ area of the bronchus. By one treatment with this source $7.5 \mathrm{~Gy}$ are delivered from a $10 \mathrm{~mm}$ distant source, with a steep decrease in the amounts delivered with greater distances of the source. In case of main motor malfunction there is a supplementary emergency motor and in addition a handcrank for manual removal of this very active source from the patient in case of a breakdown of the complete electrical system (fig 3).

The small size of the iridium source and its source cable permits the use of a flexible lightweight source guide tube of only $4 \mathrm{~mm}$ external diameter. This is

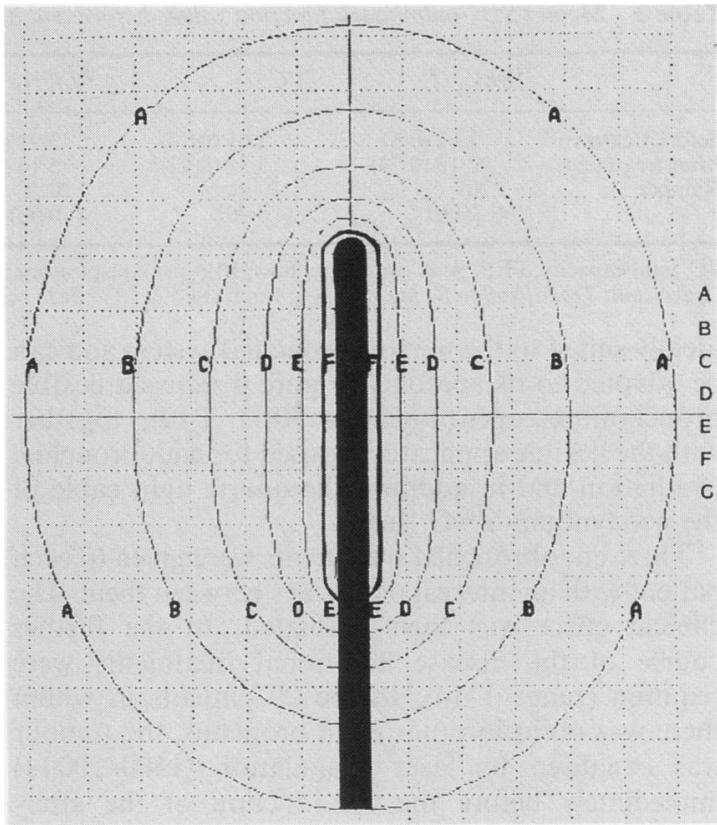

Fig 2 Shape of the afterloading catheter and isodoses by $a$ single treatment with high dose iridium-192 (source activity $20 \mathrm{Ci}$, flexible catheter diameter $4 \mathrm{~mm}$, irradiated length $6 \mathrm{~cm}$, and irradiation time 77 seconds). $A-0.47 \mathrm{~Gy}$ (47 rad); $B-0.94 G y ; C-1.87 G y ; D-3.75 G y ; E-7.5 G y$; $F-15 G y ; G-30 G y$.

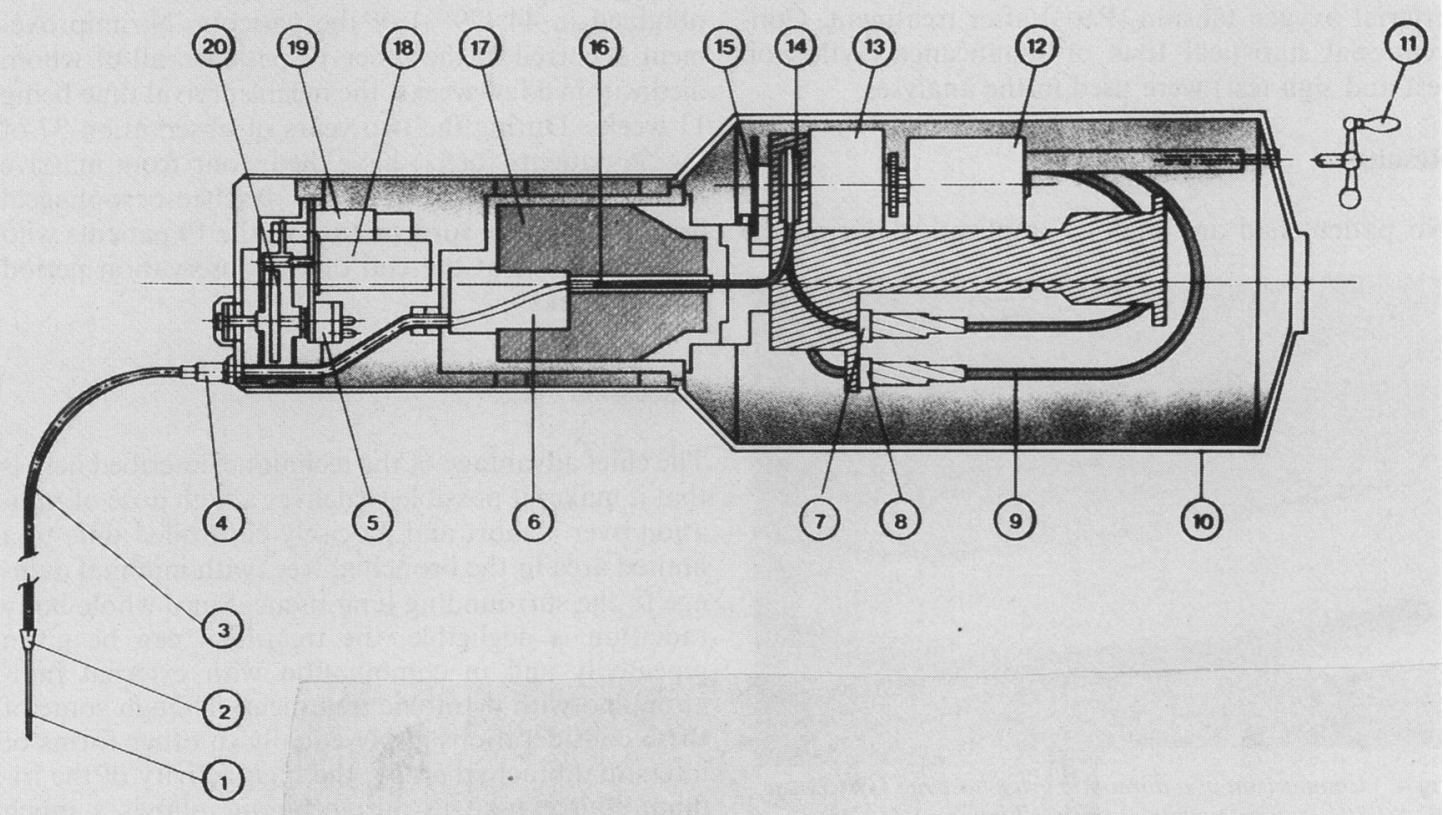

Fig 3 Diagram of the motor unit of the Gamma-Med II device. 1-needle or applicator; 2-quick connector; 3-source guide tube ( $\max 12$ pieces); 4-quick connector; 5-potentiometer for monitoring indexer position; 6-S-channel of tungsten; 7-limit switch for source end position monitoring; 8-limit switch for source end position monitoring; 9-drive cable in storage hose; 10 -housing; 11-handcrank; 12-emergency motor; 13-stepping motor; 14-gearwheel; 15-step monitoring; 16-iridium-192 source; 17-shielding of uranium; 18-magnet to mount indexer; 19-indexer motor; 20-indexer. 
Table 2 Mean (SD) pulmonary function values before and after treatment

\begin{tabular}{|c|c|c|c|c|c|c|}
\hline & $F E V_{1}(l)$ & $V C(l)$ & $\operatorname{PEF}\left(l s^{-1}\right)$ & $P I F\left(l s^{-1}\right)$ & $\operatorname{sRaw}\left(\mathrm{lcm} \mathrm{H}_{2} \mathrm{Ol}^{-1} \mathrm{~s}\right)$ & $\mathrm{PaO}_{2}(\mathrm{~mm} \mathrm{Hg})$ \\
\hline $\begin{array}{l}\text { Before treatment } \\
\text { After treatment } \\
\text { Number } \\
\text { p }\end{array}$ & $\begin{array}{l}1.62(0.6) \\
2.13(0.74) \\
20 \\
<0.001\end{array}$ & $\begin{array}{c}2.61(0.82) \\
3.31(0.97) \\
20 \\
<0.001\end{array}$ & $\begin{array}{l}3.91(1.79) \\
5.16(1.81) \\
20 \\
<0.001\end{array}$ & $\begin{array}{c}3.01(1.0) \\
5.10(2.07) \\
20 \\
<0.009\end{array}$ & $\begin{aligned} & 21 \cdot 1(14 \cdot 7) \\
11.6(4.0) & 17 \\
< & 0.001\end{aligned}$ & $\begin{aligned} 67 \cdot 7(10 \cdot 1) \\
74 \cdot 1(11 \cdot 4) \\
32 \\
<\quad 0.001\end{aligned}$ \\
\hline
\end{tabular}

VC, vital capacity; PEF, peak expiratory flow; PIF, peak inspiratory flow; sRaw, specific airways resistance; Pao ${ }_{2}$, arterial oxygen tension. Conversion: Traditional to SI units- $\mathrm{PaO}_{2}: 1 \mathrm{~mm} \mathrm{Hg} \approx 0.133 \mathrm{kPa} ; 11 \mathrm{~cm} \mathrm{H}_{2} \mathrm{Ol}^{-1} \mathrm{~s}=\left.0.11 \mathrm{kPa}\right|^{-1} \mathrm{~s}$.

ideally suited to the narrow bronchial system and can be adapted to its anatomy. Figure 4 shows a flexible bronchofibrescope (Olympus BF-1 T 10), together with the flexible applicator we used for endobronchial irradiation and in addition the quartz light cable of the neodymium-YAG laser.

Three endobronchial treatments were given to each patient with an interval of 14 days between them. The clinical effect was then evaluated. In the further course of the disease additional treatments were required (range 1-14). In the 29 patients in whom there was occlusion of a main bronchus, the tumour was canalised by laser coagulation (1500-2000 J) immediately before the introduction of the afterloading catheter. Laser canalisation was performed on 52 of the 206 occasions on which the patients were treated.

Treatment was evaluated by assessment of the change of severity of dyspnoea, the endoscopic and radiographic findings and results of pulmonary function tests and lung perfusion scans and the levels of arterial oxygen tension $\left(\mathrm{PaO}_{2}\right)$ after treatment. Conventional statistical tests of significance (Wilcoxon test and sign test) were used in the analyses.

\section{Results}

No patient had any major complication during the

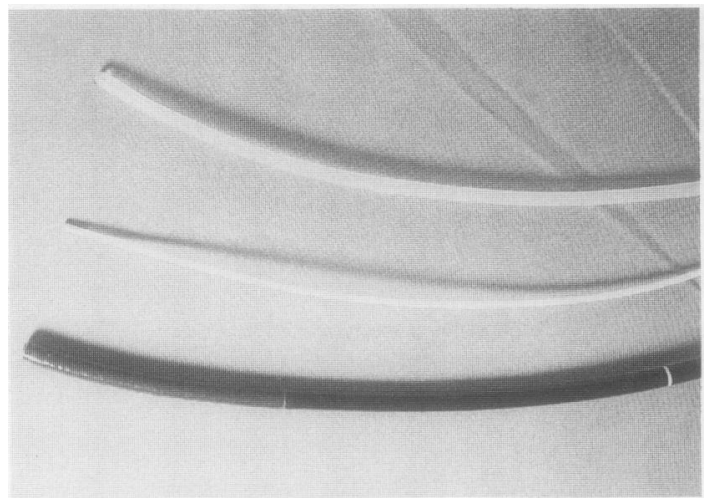

Fig 4 Comparison of a fibreoptic bronchoscope (Olympus $B F-1$ T 10), a quartz cable of the neodymium-YAG laser (Medilas II, MBB, Munich), and the $4 \mathrm{~mm}$ diameter applicator for endobronchial afterloading. procedure. The only untoward occurrence was hae- $\vec{\omega}$ morrhage (more than $50 \mathrm{ml}$ ) in two patients owing to manipulation of the afterloading catheter. The bleed- $x$ ing was treated conservatively. There were no deaths $\mathrm{N}$ during the procedure or in the immediate post- $-\checkmark$ operative period of 10 days. In $44(79 \%)$ of the 56 or patients there was a reduction in the severity of dys- $\vec{\circ}$ pnoea. This subjective improvement was reflected in $\triangle$ the endoscopy and tomography findings, tumour $\vec{c}$ regression being found in $46(82 \%)$ patients. In the $25 \stackrel{\bigodot}{=}$ patients with atelectasis radiological evidence of reaeration was found in $22(88 \%)$. Pulmonary func- $\stackrel{\infty}{\infty}$ tion data before and after treatment were available in. 20 patients. There were highly significant changes $(p<0.001)$ in the mean values of static vital capacity, $\mathrm{FEV}_{1}$, peak expiratory and inspiratory flow rates, and specific airway resistance (table 2 ). A significant improvement was also found in the perfusion of the $\stackrel{\mathbb{Q}}{\mathbb{2}}$ affected relative to the unaffected lung and in mean $\overrightarrow{\vec{\prime}}$ arterial oxygen.

Judged by all criteria, a satisfactory result was obtained in $44(79 \%)$ of the patients. No improve-? ment occurred in the other 12 patients, all of whom died within a few weeks, the mean survival time being 응 11 weeks. During the two years of observation 37 of $\underset{x}{\varrho}$ the 56 patients $(66 \%)$ have died, four from massive $\frac{0}{0}$ haemorrhage and two from tracheo-oesophageal fistula. The mean survival time of the 19 patients who were still alive at the end of the observation period $₹$ was 24 weeks.

\section{Discussion}

The chief advantage of the technique described here is $N$ that it makes it possible to deliver a high dose of radi-N ation over a short and precisely controlled time to $\mathrm{a}_{\sigma}$ limited area in the bronchial tree, with minimal damage to the surrounding lung tissue. Since whole bodyc radiation is negligible, the treatment can be given repeatedly and in combination with external radiation and with cytotoxic treatment. Though some of these considerations apply equally to other forms of interstitial brachytherapy, the high activity of the iri- $\frac{O}{\mathbb{D}}$ dium source used in our technique allows a much $\frac{2}{\rho}$ shorter irradiation time-a few minutes only. Hence it can be given under local anaesthesia to patients? 
whose poor condition precludes general anaesthesia and, as overnight irradiation is unnecessary, it can be used in outpatients as well. The absence of persistent radioactivity eliminates the necessity to isolate patients after treatment, a clear advantage over the interstitial implantation of radioactive gold grains; and the use of the remote afterloading device eliminates the problem of radiation exposure to operator and assistants. ${ }^{14}$ Performed by a trained bronchoscopist, the treatment procedure offers no major incovenience to the patients and is without serious risk.

One major disadvantage is that the treatment has to be carried out in a radiation protected operating theatre, although less room shielding is required than with cobalt -60 .

In reducing dyspnoea and improving pulmonary function in most of the patients we treated we achieved the prime objective of conferring palliative relief, especially in those patients who had relapsed after being treated by high dose of external irradiation. While we did not anticipate that the treatment would necessarily prolong survival, in the patients who responded to treatment the mean survival time was three months longer than in those who did not. This may, however, reflect differences in the extent and responsiveness of the tumour that may in turn be linked to survival.

Our results suggest that there are four specific indications for this technique. Firstly, in restoring ventilation to atelectatic regions distal to occlusive tumours, it was clearly superior to external irradiation. ${ }^{7}$ Secondly, all four patients with a recurrence of a resected carcinoma in a bronchial stump responded to treatment. Thirdly, prolonged remission (up to 15 months) and improvement in ventilatory function occurred in all five patients with adenoidcystic carcinoma. This type of tumour was responsible for the only two operative deaths that occurred in a series of 100 patients with central occlusive tumours treated by laser coagulation. ${ }^{4}$ Finally, the most important indication for endobronchial irradiation is recurrence of an endobronchial occluding tumour after the possibilities of conventional treatment have been exhausted.

Further studies are required to compare our technique with other established forms of treatment, such as electrocautery, endobronchial laser resection, and additional external irradiation. We did not consider that a controlled trial was ethically justifiable in patients with advanced disease, for most of whom no alternative treatment was available.

We are greatly indebted to Dr Jan Gregg for his valuable comments on the manuscript.

\section{References}

1 Carpenter JC, Neel HB, Sanderson DR. Cryosurgery of bronchopulmonary structures. Chest 1977;72:279-84.

2 Hooper RG, Jackson FN. Endobronchial electrocautery. Chest 1985;87:712-4.

3 Dumon JF, Reboud E, Garbe L, Aucomte F, Meric B. Treatment of tracheobronchial lesion by laser photoresection. Chest 1982;81:278-84.

4 Dierkesmann R. Rekanalisation bronchialer Tumorstenosen mit dem Neodym-YAG Laser. Internist 1982; 23:283-6.

5 Hetzel MR, Nixon C, Edmonstone WM, et al. Laser therapy in 100 tracheobronchial tumours. Thorax 1985;40:341-5.

6 Toty L, Personne C, Colchen A, Vourch G. Bronchoscopic management of tracheal lesions using the neodym-yttrium-aluminium-garnet laser. Thorax 1981;36:175-8.

7 Slawson RG, Scott RM. Radiation therapy in bronchogenic carcinoma. Radiology 1979;132:175-6.

8 Schlungbaum W, Blum H, Brandt HJ. Ergebnisse der endobronchialen Strahlentherapie des Bronchuskarzinoms. Radiologia Austriaca 1962;13(3):201-4.

9 Law MR, Henk JM, Goldstraw P, Hodson ME. Bronchoscopic implantation of radioactive gold grains into endobronchial carcinomas. Br J Dis Chest 1985;79: 147-51.

10 Hilaris BS, Dattatireyudu N, Beattie EJ, Martini N. Values of perioperative brachytherapy in the management of non-oat cell carcinoma of the lung. Int $J$ Radiat Oncol Biol Phys 1983;9:1161-6.

11 Hilaris BS, Martini N. Interstitial brachytherapy in cancer of the lung: a 20 year experience. Int J Radiat Oncol Biol Phys 1979;5:1951-6.

12 Hilaris BS, Batata MA, eds. Brachytherapy oncology 1983 (advances in prostate and other cancers): a collection of papers presented at fourth annual brachytherapy update. New York: Memorial Sloan-Kettering Cancer Center, 1983:114-6.

13 Rooney SR, Goldiner PL, Bains MS, Hilaris B, Jain SJ. Anaesthesia for the application of endotracheal and endobronchial radiation therapy. $J$ Thorac Cardiovasc Surg 1984;87:693-7.

14 Busch M, Makoski B, Sauerwein K. Das Essener Nachlade-Verfahren für die intrakavitäre Strahlentherapie. Strahlentherapie 1977;153:581-8. 